Binghamton University

The Open Repository @ Binghamton (The ORB)

2015

\title{
A Systematic Evaluation of a Multidisciplinary Social Work- Lawyer Elder Mistreatment Intervention Model
}

Victoria M. Rizzo

Binghamton University--SUNY, vrizzo@binghamton.edu

David Burnes

Amy Chaify

Follow this and additional works at: https://orb.binghamton.edu/social_work_fac

Part of the Social Work Commons

\section{Recommended Citation}

Rizzo, Victoria M.; Burnes, David; and Chaify, Amy, "A Systematic Evaluation of a Multidisciplinary Social Work- Lawyer Elder Mistreatment Intervention Model" (2015). Social Work Faculty Scholarship. 6. https://orb.binghamton.edu/social_work_fac/6

This Article is brought to you for free and open access by the Social Work at The Open Repository @ Binghamton (The ORB). It has been accepted for inclusion in Social Work Faculty Scholarship by an authorized administrator of The Open Repository @ Binghamton (The ORB). For more information, please contact ORB@binghamton.edu. 
This article was downloaded by: [Victoria Rizzo]

On: 03 May 2013, At: 14:19

Publisher: Routledge

Informa Ltd Registered in England and Wales Registered Number: 1072954 Registered office: Mortimer House, 37-41 Mortimer Street, London W1T 3J H, UK

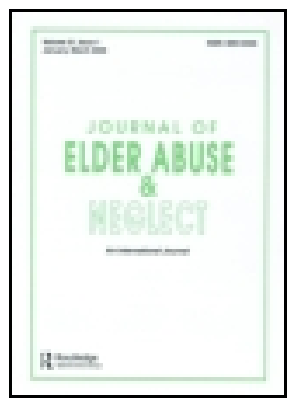

\title{
J ournal of Elder Abuse \& Neglect
}

Publication details, including instructions for authors and subscription information: http:// www.tandfonline.com/loi/ wean20

\section{A Systematic Evaluation of a Multidisciplinary Social Work-Lawyer Elder Mistreatment Intervention Model}

\author{
Victoria Marie Rizzo LCSW-R PhD ${ }^{a}$, David Burnes ${ }^{b} \&$ Amy Chalfy ${ }^{c}$ \\ ${ }^{a}$ Columbia University, School of Social Work, Mail Code 4600, 1255 Amsterdam Avenue, New \\ York, NY , 10027, United States \\ ${ }^{b}$ Columbia University, School of Social Work, 1255 Amsterdam Avenue, New York, 10027 , \\ United States \\ c J ewish Association Serving the Aging, 247 West 37th Street, New York, 10018, United \\ States \\ Accepted author version posted online: 02 May 2013.
}

To cite this article: Victoria Marie Rizzo LCSW-R PhD , David Burnes \& Amy Chalfy (2013): A Systematic Evaluation of a Multidisciplinary Social Work-Lawyer Elder Mistreatment Intervention Model, J ournal of Elder Abuse \& Neglect, DOI: $10.1080 / 08946566.2013 .792104$

To link to this article: http:// dx.doi.org/ 10.1080/08946566.2013.792104

Disclaimer: This is a version of an unedited manuscript that has been accepted for publication. As a service to authors and researchers we are providing this version of the accepted manuscript (AM). Copyediting, typesetting, and review of the resulting proof will be undertaken on this manuscript before final publication of the Version of Record (VoR). During production and pre-press, errors may be discovered which could affect the content, and all legal disclaimers that apply to the journal relate to this version also.

\section{PLEASE SCROLL DOWN FOR ARTICLE}

Full terms and conditions of use: http://www.tandfonline.com/page/terms-and-conditions

This article may be used for research, teaching, and private study purposes. Any substantial or systematic reproduction, redistribution, reselling, loan, sub-licensing, systematic supply, or distribution in any form to anyone is expressly forbidden.

The publisher does not give any warranty express or implied or make any representation that the contents will be complete or accurate or up to date. The accuracy of any instructions, formulae, and drug doses should be independently verified with primary sources. The publisher shall not be liable for any loss, actions, claims, proceedings, demand, or costs or damages whatsoever or howsoever caused arising directly or indirectly in connection with or arising out of the use of this material. 


\section{ACCEPTED MANUSCRIPT}

\section{A Systematic Evaluation of a Multidisciplinary Social Work- Lawyer Elder Mistreatment Intervention Model}

Victoria Marie Rizzo, LCSW-R, PhD (Corresponding Author)

Email: vr2178@columbia.edu

Columbia University, School of Social Work, Mail Code 4600, 1255 Amsterdam Avenue, New York, NY 10027 United States

David Burnes

Email: db2735@columbia.edu

Columbia University, School of Social Work, 1255 Amsterdam Avenue, New York, 10027

United States

Amy Chalfy

Email: achalfy@jasa.org

Jewish Association Serving the Aging, 247 West 37th Street, New York, 10018 United States

\section{Abstract}

This study introduces a conceptually-based, systematic evaluation process employing multivariate techniques to evaluate a multidisciplinary social work/lawyer intervention model (JASA-LEAP). Logistic regression analyses were used with a random sample of case records (n $=250$ ) from three intervention sites. Client retention, program fidelity, and exposure to multidisciplinary services were significantly related to reduction in mistreatment risk at case closure. Female gender, married status and living with perpetrator significantly predicted unfavorable outcomes. This study extends the elder mistreatment program evaluation literature beyond descriptive/bivariate evaluation strategies. Findings suggest that a multi-disciplinary social work/lawyer elder mistreatment intervention model is a successful approach.

\section{ACCEPTED MANUSCRIPT




\section{ACCEPTED MANUSCRIPT}

\section{Keywords:}

elder abuse evaluation

multi-disciplinary elder abuse intervention

evidence-based elder abuse intervention

Received: 7 Jan 2013; Accepted 31 Mar 2013

\section{Introduction}

Elder mistreatment includes physical, sexual, emotional, and financial abuse or neglect towards an elder by a person in a relationship of trust (National Research Council, 2003). Estimated one-year prevalence of elder mistreatment among community-dwelling elders in the United States (U.S.) is 7.6\% - 11.4\% (Acierno et al., 2010; Lachs \& Berman, 2011). With the segment of the population aged 65 and older expected to double by 2030 (CDCP, 2007), the absolute number of mistreated elders will increase, challenging the preparedness and effectiveness of social service programs helping this population. Unresolved elder mistreatment ${ }^{1}$ is associated with devastating health and psychosocial consequences including premature death, increased mortality, morbidity, hospitalization, disability, nursing home placement, poor mental/physical health, and financial loss (Dong, Simon, \& Evans, 2012; Dong et al., 2009; Fisher \& Regan, 2006; Lachs, Williams, O’Brien, \& Pillemer, 2002; Lachs, Williams, O'Brien,

\footnotetext{
${ }^{1}$ In this study, the definition of elder mistreatment used is the one that guides the intervention program under evaluation. Elder abuse is "any form of mistreatment that results in harm or loss to an older person" (Schecter \& Dougherty, 2009, p. 71). Categories include: physical, sexual, financial, passive, and self-neglect as well as active neglect, which is the willful deprivation of resources necessary to ensure the health and well-being of the older adult.
} 


\section{ACCEPTED MANUSCRIPT}

Pillemer, \& Charlson, 1998). Research has established elder mistreatment as a pervasive problem; however, elder mistreatment research remains at a nascent stage in learning how to intervene with victims.

Researchers and practitioners have concluded that the development and improvement of elder mistreatment social service intervention evaluation strategies is a research priority, with a need to formulate more systematic, rigorous evaluation approaches (Pillemer et al., 2011; Stolee, Hiller, Etkin, \& McLeod, 2012). A National Academies of Science panel was convened a decade ago to assess the state of elder mistreatment research. The panel concluded that while elder mistreatment intervention models were routinely presented in a descriptive manner, these programs had not been subjected to systematic evaluation (National Research Council, 2003). At present, thousands of case workers throughout the United States are implementing a growing number of social service interventions to alleviate cases of elder mistreatment with little research guidance as to which programs actually work (Ploeg, Fear, Hutchison, MacMillan, \& Bolan, 2009; Stolee et al., 2012). Public and private resources are invested in programs that have no proven efficacy, which means elder mistreatment victims are subjected to interventions that may be ineffective. Elder mistreatment program evaluation research lacks a systematic, conceptuallybased evaluation approach to inform the development of effective intervention strategies.

\section{Challenges in Elder Mistreatment Intervention Research}

The lack of substantive elder mistreatment program evaluation and intervention research is not surprising given the challenges that can impede the development of robust prospective, experimental or quasi-experimental research designs with the abused elder population. 


\section{ACCEPTED MANUSCRIPT}

Challenges are related to ethics; consent; human subject protection rules; mandatory reporting obligations; participant access and recruitment; agency cooperation; and a paucity of resources; (Connolly, 2008; Pillemer et al., 2011). With up to $94 \%$ of cases remaining hidden in the community, abused elders are a particularly difficult population to recruit (Lachs \& Berman, 2011). Given the emergency nature of mistreatment situations, referrals must be responded to immediately; there is little time for screening and consent protocols or administering study instruments; and ethical issues arise in assigning subjects into a research arm that denies optimal services. Elders with cognitive impairment are at higher risk for mistreatment (Mosqueda \& Dong, 2011). There are difficulties obtaining consent from an elder lacking capacity; proxies are reluctant to provide consent; and there can be concern that the family proxy may also be a perpetrator. In many states, elders are reluctant to participate in research or provide accurate disclosure information due to mandatory reporting ramifications. Debate also persists as to whether participation in elder mistreatment intervention research itself poses increased risk or stress to the subject (Connolly, 2008; Pillemer et al., 2011).

While researchers and institutional review boards work through these challenges, case record analysis is the most common study design (Burnes \& Lachs, 2012). However, elder mistreatment case record studies have been criticized as limited by small sample sizes; convenience sampling; unreliable, single-rater measurement procedures; inadequate means to deal with missing data; and/or univariate/bivariate statistical methods. The present study seeks to build upon and address these case record design methodological design limitations. To our knowledge, this is the first elder mistreatment study to employ multivariate statistical techniques

\section{ACCEPTED MANUSCRIPT




\section{ACCEPTED MANUSCRIPT}

as a strategy for evaluation. It also follows a systematic, conceptually-based evaluation approach to address the fundamental research question: Does the elder mistreatment intervention work?

\section{A Multi-disciplinary Approach}

The elder mistreatment literature advocates for a multi-disciplinary model of intervention to alleviate cases of elder mistreatment (Imbody \& Vandsburger, 2011; Mosqueda \& Dong, 2011). A multi-disciplinary approach provides the necessary diversity of professional resources and skills, used at different points along the assessment and intervention process, to problemsolve and resolve complex, multi-faceted cases of elder mistreatment. For example, communitybased multi-disciplinary teams have emerged throughout the country as a way to synergize the resources of diverse providers (Navarro, Wilber, Yonashiro, \& Homeier, 2010). Nevertheless, although the rationale for advocating for this preferred model orientation is strong, empirical evidence from research supporting a multi-disciplinary model is weak. Few empirical analyses in the literature have shown the benefits of this intervention orientation. Several calls have been made for evaluations of multi-disciplinary elder mistreatment intervention models (Connolly, 2008; National Research Council, 2003).

Social workers and lawyers represent two key professions involved in treatment plans to support elder victims and alleviate risk of mistreatment (Brownell \& Wolden, 2002; Teaster, Nerenberg, \& Stansbury, 2003). In community-based social service programs, social workers are involved with receiving the referral, conducting initial assessment and investigation to substantiate the mistreatment, and providing ongoing psychosocial support to execute a treatment plan. Social work services can include one or more of the following: case management; 


\section{ACCEPTED MANUSCRIPT}

counseling and mental health support; support groups; financial assistance, alternative housing, police involvement; installation of home security devices or lock replacement; and coordinating external referrals [i.e. legal, health, district attorney, adult protective services (APS) etc.]. Lawyers are often required in cases of elder mistreatment to facilitate legal measures necessary to increase safety and protection of the elder, including orders of protection, power of attorney, guardianship, modification of a will, evictions, and mental hygiene warrants.

While social work services are a critical component in both social service and criminal justice efforts, Brownell and Wolden (2002) found that the availability of legal interventions is a significant factor associated with case resolution, particularly in cases involving financial abuse. Ernst and Smith (2012) found that while social workers alone were more likely to confirm certain forms of abuse, a multi-disciplinary approach resulted in a greater reduction of risk in cases of elder mistreatment. Knowledge and skill set differences between social workers and lawyers in the context of elder mistreatment interventions are complimentary; however, these two professional services are typically provided independently in separate programs in the community. This silo structure of integral elder mistreatment intervention services can create barriers and inefficiencies, which can disservice the elder and delay and/or prevent progress towards safety.

\section{The JASA-LEAP Intervention}

The present study evaluates a multi-disciplinary elder mistreatment intervention model designed to alleviate cases of elder abuse and neglect, which integrates the expertise of social workers and lawyers under the same roof, namely the Jewish Association Serving the Aging 


\section{ACCEPTED MANUSCRIPT}

(JASA) Legal/Social Work Elder Abuse Prevention Program (LEAP) in New York City (NYC). JASA-LEAP is the largest community-based elder abuse social service program in NYC, handling over 700 cases of abuse or neglect annually across three boroughs (Manhattan, Brooklyn, and Queens). Assisting elders aged 60 years and older, JASA-LEAP referrals are accepted from all sources, including self, family, friends, social services, district attorney, police, hospitals, clinics, APS, banks, and anonymous sources. Within JASA-LEAP, the social work and legal disciplines work in tandem, not in silos, throughout the intervention process. By integrating these professional services, the JASA-LEAP model is intended to increase program efficiency, resources, specialization and capacity to serve victims immediately, without being impeded by or dependent on, the coordination and elicitation of external services.

After completing a comprehensive assessment to determine the elders' ability to: 1) make decisions; 2) understand and process information, and 3) communicate with and direct others to carry out their wishes, the social worker and lawyer develop an individualized treatment plan focused on the elders' assessed level of risk. Social workers assist clients with applying for benefits/entitlements and Crime Victim Board compensation. They help elders secure emergency funds, locks and alarms; conduct security assessments to help clients regain a sense of security and safety; coordinate referrals; and provide psychosocial case management, counseling, support groups and education. Lawyers assist with legal interventions to ensure the elders' safety, including but not limited to, orders of protection, eviction notices, recovery of real property, and long-term care planning (e.g., living wills and durable powers of attorney). Throughout the intervention, the social workers and lawyers communicate with each other; and, as a team they 


\section{ACCEPTED MANUSCRIPT}

provide advocacy within the legal and social services systems to ensure elders' needs are met. Schecter and Dougherty (2009) provide a more detailed description of JASA-LEAP.

\section{Purpose}

The purpose of this study is to: 1) address calls in the literature to evaluate a multidisciplinary elder mistreatment intervention model and determine if empirical evidence exists to support the prevailing orientation towards multidisciplinary models; and, 2) advance the elder mistreatment program evaluation literature by using a conceptually-based, systematic evaluation process employing multivariate statistical techniques. The specific research hypotheses tested to measure JASA-LEAP success were: Hypothesis 1 (H1): Outcomes for client retention and mistreatment status at case closure (MSCC) in this study will be the same, or better, than the same outcomes in previous studies; Hypothesis 2 (H2): Acceptance of JASA-LEAP services by clients will be associated with reduced risk of mistreatment at case closure; Hypothesis 3 (H3): Higher levels of program fidelity (client exposure to intended JASA-LEAP model) will be associated with reduced risk of mistreatment at case closure; and, Hypothesis 4 (H4): Clients participating in a multi-disciplinary treatment plan (lawyer and social work services) will have more favorable MSCC compared to clients pursuing a social work-only intervention plan. 


\section{ACCEPTED MANUSCRIPT}

\section{Methods}

\section{Sample and Data}

A multi-site, random sample $(\mathrm{n}=250)$ of JASA-LEAP case records, closed between 2009 and 2011, was generated using systematic random sampling. Sampling was stratified according to program borough size, in that the number of records drawn per borough was proportional to the volume of cases handled by each borough annually: Manhattan (15\%), Brooklyn (40\%), and Queens (45\%). Sample size was determined based on power analysis and resources available for data collection. Using reasonable assumptions of a medium effect size, an alpha level of 0.05 , and accounting for three sites of data collection, a sample of 250 cases provided a more than adequate 0.99 power level. Seventeen cases in which mistreatment was unsubstantiated following investigation were omitted from analysis since no intervention took place. Table 1 provides a description of the study sample characteristics. Study sample gender, race and age characteristics are consistent with recent socio-demographic trends of documented social service system elder mistreatment victim characteristics in New York City (Lachs \& Berman, 2011); victims were mostly female, non-Caucasian, and aged 60 to 75 years.

Record data were manually extracted from routine, categorized assessment and case closure forms that, in consultation with the first author (VMR), were originally constructed for the purpose of research and uniform/un-biased caseworker data collection across JASA-LEAP sites. A data collection tool designed via an iterative process of testing with a small sample of case records was used. To ensure reliability of the collection tool, data from an initial sub-sample

\section{ACCEPTED MANUSCRIPT




\section{ACCEPTED MANUSCRIPT}

of case records $(n=20)$ were extracted by two independent researchers and verified for consistency. To ensure reliability of data coding and interpretation, collection tool data for all case records were coded and interpreted by two trained independent raters; a third party researcher was consulted if the two independent raters diverged.

\section{Variables}

Consistent with other elder mistreatment intervention evaluation studies (Burnes \& Lachs, 2012), outcome variables included retention and MSCC. Retention refers to the classification of a victim as accepting or refusing services. The opportunity to execute a program intervention to alleviate elder mistreatment is contingent upon the ability of the program to retain clients. Similar to previous studies measuring the retention outcome (Lithwick, Beaulieu, Gravel, \& Straka, 2000; Neale, Hwalek, Goodrich, \& Quinn, 1996; Roberto, Teaster, \& Duke, 2004; Wolf \& Pillemer, 2000), retention in this study was measured as a dichotomous variable based on whether or not the client accepted any services (no $=0$; yes $=1)$.

Corresponding with the main program goal, MSCC refers to the extent that the substantiated mistreatment situation has been alleviated following social service intervention. Following recommendations of Wolf and Pillemer (2000), the MSCC outcome was operationalized according to level of future risk of mistreatment. This operationalization recognizes that multiple solutions exist to alleviate elder mistreatment and that a close-ended, singular goal of complete case resolution is often not possible, realistic or desired by the victim at the time of case closure. MSCC was measured as a dichotomous outcome variable (reduced risk of further mistreatment $=0$; risk of mistreatment remains high or unchanged $=1$ ). A

\section{ACCEPTED MANUSCRIPT}




\section{ACCEPTED MANUSCRIPT}

standardized, validated MSCC measurement instrument does not exist (Anthony, Lehning, Austin, \& Peck, 2009). Subjective MSCC researcher rating is standard research practice in the field; however, the present study emphasized the use of multiple raters to increase measurement reliability. Allocation of cases into MSCC category was assigned, based on record process notes and case closure summary forms, by two independent researchers to ensure inter-rater reliability; a third party researcher was consulted on five occasions when the two independent raters diverged. Allocation into MSCC category was guided by the question: To what extent does the risk of mistreatment harm remain at the time of case closure? Assignment into the high/unchanged category implied that no progress had been made on alleviating the substantiated mistreatment situation or in lessoning the threat of harm. Clients involved with these cases often denied or resisted JASA-LEAP services and for a variety of circumstances (e.g., preserving family dynamics, protecting a familial perpetrator from legal/justice system, maintaining stability of status-quo) could not pursue interventions necessary to alleviate the mistreatment situation. A reduced risk case allocation meant that protective steps (e.g., order of protection, housing relocation, perpetrator eviction, home security, financial protection, psychosocial individual/family counseling, support groups) had been taken towards alleviating risk of future mistreatment.

Key predictor variables in the analytic plan were related to level of JASA-LEAP program fidelity (extent to which intervention model was executed as intended) and intervention type (multidisciplinary versus social work-only). JASA-LEAP clients are offered a tailored intervention plan including services that respond to the unique needs of the mistreatment situation. The services offered depend on several factors, including mistreatment type and severity, living arrangement, proximity to perpetrator, level of social isolation, health status, etc.

\section{ACCEPTED MANUSCRIPT}




\section{ACCEPTED MANUSCRIPT}

As a voluntary program, clients can decline services. For example, frail elders may accept social work services and decline legal interventions since the latter services are typically more intrusive, potentially life-altering, and carry higher risk of severing family relationships, criminally implicating a familial perpetrator, or causing instability. Level of program fidelity was measured as a continuous ratio variable ( 0 to 1 ) calculated by dividing the number of services a client pursued by the number of services the client was offered as a part of a JASA-LEAP treatment plan. This variable represents the extent to which the JASA-LEAP intervention had the opportunity to be executed as it was intended, with higher scores representing higher program fidelity. The mean program fidelity ratio score was $0.47(\mathrm{SD}=0.37)$. A binary variable, intervention type, was created to denote whether or not a client was exposed to a combined social work/legal intervention plan (social work services only $=0$; multi-disciplinary social work-legal services $=1$ ).

In previous studies examining the MSCC outcome, victim social support; absence of illness; change in living situation; dependence (e.g., cognitive impairment); and separation from the perpetrator have been associated with improved MSCC, while victim minority racial group; psychological and physical abuse; abuse severity; and victim-perpetrator interdependence have been negatively related with favorable MSCC (Roberto et al., 2004; Vladescu et al., 2000; Wolf \& Pillemer, 1989, 2000). With the exception of victim-perpetrator interdependence and mistreatment severity/frequency (unavailable in dataset), multivariate regression models in the present study adjusted for the following covariate variables, which were identified in the aforementioned literature as associated with elder mistreatment MSCC outcomes and/or represent important case socio-demographic variables to control for: borough

\section{ACCEPTED MANUSCRIPT}




\section{ACCEPTED MANUSCRIPT}

(Manhattan/Queens/Brooklyn); referral source (community/family/self); client gender (male/female); client racial group (Caucasian/minority); client age (continuous 60 to 96 years); client English proficiency (no/yes); client marital status (married/non-married); mistreatment type (financial/emotional/physical/sexual/neglect/multiple forms); client physical health issue (no/yes); client dementia (no/yes); client social support (low/moderate/high); client living arrangement (with perpetrator/without perpetrator); perpetrator gender (male/female); and perpetrator substance abuse (no/yes). Social support level was measured in response to the question: To what extent client feels he/she has enough people to talk to about difficulties? Among five available response options, responses of "never" or "rarely" were operationalized as low social support, "sometimes" was operationalized as moderate, and "most of the time" or "always" were operationalized as high social support. Perpetrator substance abuse was defined as alcohol or drug dependence at the time of initial client assessment, as reported by the client or evidenced in documentation from the referral.

Multiple imputation (MI) was used to account for missing values - a fully conditional specification (FCS) MI approach employing an iterative Markov chain Monte Carlo method. Ten complete imputed datasets were pooled for analysis.

\section{Analytic Plan}

The following analytic plan was used to test the four research hypotheses:

H1: Outcome rates were compared to those found in previous studies. For the retention outcome previous research reported victim rate of refusal of services between $13 \%$ and $58 \%$

\section{ACCEPTED MANUSCRIPT}




\section{ACCEPTED MANUSCRIPT}

(Lithwick et al., 2000; Neale et al., 1996; Roberto et al., 2004; Shiferaw et al., 1994; Wolf \& Pillemer, 2000). Regarding the MSCC outcome, previous research reported rates of reduced risk, lessened abuse or partial/complete resolution from $56 \%$ to $84 \%$ and rates of ongoing high risk or unresolved abuse between 16\% and 44\% (Cripps, 2001; Kurrle, Sadler, Lockwood, \& Cameron, 1997; Lithwick et al., 2000; Neale et al., 1996; Vladescu et al., 2000; Wolf \& Pillemer, 1989, 2000). This comparative means of evaluation lacks validity, since it was done across studies and programs with considerably different circumstances and research conditions. However, the comparison provides a useful, preliminary point of reference to screen for red flags or outlier outcome rates that may require consideration before moving forward with further, more sophisticated analysis.

H2: In a successful program, client acceptance of services ought to provide the elder with a higher likelihood of reducing risk of mistreatment than remaining at high/unchanged risk at case closure. A multivariate logistic regression model (Model 1), controlling for key covariates, was used to test the hypothesis of a negative relationship between retention and MSCC acceptance of services is associated with a reduction in risk of mistreatment.

H3: In a successful program, a greater extent of program fidelity ought to be associated with more favorable outcomes. A multivariate logistic regression model (Model 2), controlling for key covariates, was used to test the hypothesis that higher levels of program fidelity were associated with a reduction in risk of MSCC.

H4: JASA-LEAP clients are not always exposed to the combined social work/legal model if services are declined. Among clients who accepted at least one service $(n=167)$, group

\section{ACCEPTED MANUSCRIPT}




\section{ACCEPTED MANUSCRIPT}

comparisons were made on key covariates between clients exposed to social work services only $(\mathrm{n}=63 ; 37.7 \%)$ and clients exposed to combined social work/legal services $(\mathrm{n}=104,62.3 \%)$. The groups differed significantly on age, $\mathrm{t}(111.46)=3.94, \mathrm{p}<0.001$, with older clients less

likely to pursue legal interventions, and with respect to perpetrator substance use, $\left[\chi^{2}(1,120)=\right.$ 5.35, $\mathrm{p}<0.05$ ], with legal services more likely to be used when the perpetrator has a substance abuse problem. A multivariate logistic regression model (Model 3), controlling for key covariates, was used to test the hypothesis that clients pursuing a multidisciplinary intervention plan would have more favorable MSCC compared to victims pursuing social work services only.

Multicollinearity diagnostics and correlations were examined to ensure that independent variables in models were not highly correlated. Independent variable correlations ranged in magnitude from 0 and 0.26 and had tolerance of 0.75 or above, indicating an absence of multicollinearity. Analysis was conducted using SPSS Statistics, v19.

\section{Results}

H1: JASA-LEAP rate of retention was $71.7 \%$. At case closure, JASA-LEAP rate of reduced risk of mistreatment was $68.2 \%$. The rate of high/unchanged risk was $31.8 \%$.

$\mathrm{H} 2$ : Table 2 (Model 1) reveals the results of the logistic regression analysis used to examine the hypothesis of a negative relationship between client retention and MSCC. Client retention was a significant negative predictor of $\operatorname{MSCC}(\beta=-4.17$;E $=0.61 ; \mathrm{p}<0.001)$, with retained clients having 0.02 times lower odds than non-retained clients of remaining at high/unchanged mistreatment risk. Among the 14 covariates in the model, client gender was a significant positive

\section{ACCEPTED MANUSCRIPT}




\section{ACCEPTED MANUSCRIPT}

predictor of MSCC, with females having 6.37 greater odds than males of no reduction in mistreatment risk $(\beta=1.85 ; \mathrm{SE}=0.70 ; \mathrm{p}<0.01)$, and client marital status was a significant negative predictor of MSCC, with non-married clients having 0.21 times lower odds than married clients of remaining at high/unchanged mistreatment risk at case closure $(\beta=-1.55$; SE $=0.63 ; \mathrm{p}<0.05)$. Living arrangement status demonstrated borderline significance $(\beta=-1.07 ; \mathrm{SE}$ $=0.55 ; \mathrm{p}=0.055)$; clients living without the perpetrator had lower odds of remaining at high/unchanged mistreatment risk compared to clients living with the perpetrator.

H3: Table 2 (Model 2) reports the results of the logistic regression analysis used to test the hypothesis that higher level of program fidelity is associated with a reduction in risk of mistreatment at case closure. Program fidelity was a significant negative predictor of MSCC $(\beta=$ -6.48; SE $=1.04 ; \mathrm{p}<0.001$ ), with higher levels of fidelity scores associated with lower odds of remaining at a high/unchanged mistreatment risk. Again, client gender was a significant positive predictor of $\operatorname{MSCC}(\beta=1.77 ; \mathrm{SE}=0.67 ; \mathrm{p}<0.01)$ and client marital status was a significant negative predictor of $\operatorname{MSCC}(\beta=-1.40 ; \mathrm{SE}=0.66 ; \mathrm{p}<0.05)$. Client living arrangement was a significant negative predictor of MSCC, with clients living without the perpetrator having 0.27 times lower odds than clients living with the perpetrator of remaining at a high/unchanged risk of mistreatment $(\beta=-1.32 ; \mathrm{SE}=0.55 ; \mathrm{p}<0.05)$.

H4: Table 2 (Model 3) shows the results of the logistic regression analysis used to examine the hypothesis that clients pursuing a multi-disciplinary intervention will have more favorable MSCC compared to clients participating in a social work only intervention. It was necessary to include fewer covariate independent variables in this model to account for risks of

\section{ACCEPTED MANUSCRIPT}




\section{ACCEPTED MANUSCRIPT}

non-convergence and model instability with a smaller sub-sample size. Covariates of referral source and English proficiency were dropped from Model 3 since previous research does not find evidence for these factors to be viewed as priorities and they had not shown significance in the previous two multivariate models. Mistreatment type was excluded since it was a variable with many (five) categories and had not shown significance in the previous two multivariate models. Intervention type was a significant negative predictor of $\operatorname{MSCC}(\beta=-1.57 ; \operatorname{SE}=0.66 ; p<0.05)$, with clients exposed to a multidisciplinary intervention having 0.21 times lower odds than clients exposed to a social work only intervention of no reduction of mistreatment risk.

\section{Discussion}

The present study followed a conceptually-based, systematic evaluation process employing multivariate statistics to evaluate a multi-disciplinary social work/lawyer intervention model for elder mistreatment alleviation. Thus, it addresses a need to develop more rigorous program evaluation strategies that can inform evidence-based interventions (Pillemer et al., 2011; Stolee et al., 2012) and a call from the field to empirically evaluate multi-disciplinary models.

JASA-LEAP outcome rates were placed in the context of rates of similar outcome constructs in the literature. This first evaluation step was employed more as a useful, preliminary point of reference to screen for outliers than as a meaningful comparative means of evaluation such a comparison lacks validity without similar study/program conditions (i.e. case worker experience, referral sources, inclusion criteria, client motivation). As expected, JASA-LEAP

\section{ACCEPTED MANUSCRIPT}




\section{ACCEPTED MANUSCRIPT}

outcome rates fell in the middle of the literature ranges and, therefore, did not represent a red flag or cause for concern to proceed in the evaluation process.

An assumption underlying the present evaluation plan is that clients who choose to accept services from a program ought to experience an improvement in MSCC. A program in which clients are as likely to remain at a high/unchanged risk of mistreatment status as they are to experience a reduction in risk of mistreatment would be deemed ineffective. Therefore, a significant relationship between retention and MSCC provides evidence that a program is working. As expected, findings indicated that clients who accepted JASA-LEAP services were more likely to experience a reduction in risk of future mistreatment upon case closure.

We constructed a ratio variable to operationalize level of program fidelity. This variable represents a proxy of the intervention model, or the extent to which the intervention program had the opportunity to be executed as it was intended. Findings revealed that higher levels of JASALEAP intervention model fidelity were associated with more favorable outcomes at case closure - evidence that the program is working. However, these results may, in part, be due to selection bias, since analysis included those who were not retained and, therefore, were less likely to experience a reduction in mistreatment risk (Table 1).

Findings from this study support the prevailing, largely un-tested, position in the elder mistreatment literature to use multi-disciplinary models to intervene with victims of elder mistreatment. In particular, findings provide support for an integrated social work/legal interdisciplinary model. Clients pursuing combined social work and legal services were more likely to have a reduction in mistreatment risk compared to clients pursuing social work services

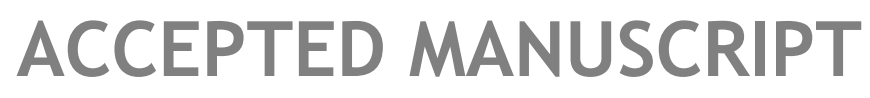




\section{ACCEPTED MANUSCRIPT}

only. These results extend bivariate findings from a previous study showing a significant association between multidisciplinary services and reduction of mistreatment risk in cases of elder mistreatment (Ernst \& Smith, 2012). Further research is required to isolate core components, mechanisms of change, and aspects of the social work/legal combination that are responsible for mediating the intervention's effects on outcomes. By integrating two integral professions in a complimentary manner, the JASA-LEAP model is intended to increase program efficiency and capacity, drawing on a diversity of skills and resources, in order to address the immediate, multi-faceted needs of elder mistreatment victims.

Client gender (being female), marital status (being married), and living arrangement (living with the perpetrator) emerged as significant covariate predictors of unfavorable MSCC. Regarding living arrangement, the multivariate finding in this study extends previous bivariate results that a change in living situation or separation from the perpetrator is associated with improved MSCC (Wolf \& Pillemer, 1989; 2000). Correlation evidence has found that a perpetrator is less likely to exit the mistreatment situation if the perpetrator is a spouse (Vladescu et al., 2000), which may help explain why married clients in the present study experienced unfavorable MSCC outcomes. Although routinely included in previous bivariate studies, gender has never shown significance as a predictor of case outcomes. The emergence of gender in the present study may be due to sample bias or a result of examination in the context of multivariate analysis. Further research is necessary to understand gender as a predictor of outcomes.

Findings in this study should be interpreted within the limitations of a case record review design. As agency case records are not directly designed around a structured research agenda, 


\section{ACCEPTED MANUSCRIPT}

limitations of this design include increased risk of systematic error in the form of missing data, inconsistent record information, and caseworker bias. This study sought to build on previous elder mistreatment case record research methodology and implement measures to reduce systematic error in the following ways: large sample, random sampling of records, multi-site data collection, extraction of data from routine record forms originally constructed for the purpose of research and uniform/un-biased caseworker data collection, multiple imputation techniques to deal with missing data, use of multiple independent raters of data coding/interpretation, and use of multivariate methods. As data was collected from one social service program in the NYC geographic area, results in this study cannot necessarily be generalized to all elder mistreatment interventions. Future elder mistreatment intervention research should find ways to develop prospective, quasi-experimental and experimental designs. Without an experimental design, the present study cannot make causal conclusions regarding significant associations. However, multivariate analysis provides greater validity of associations by controlling for key confounding factors. To our knowledge, this is the first study within the elder mistreatment program evaluation literature to employ multivariate analysis for the purpose of elder mistreatment program evaluation. An absence of psychometrically sound MSCC outcome measures limits the field to subjective measurement methods; development of a valid MSCC outcome instrument for use in social service intervention settings is a priority for future research. Future studies should be designed to include recidivism as a follow-up elder mistreatment intervention outcome.

In conclusion, this study found evidence that a multi-disciplinary social work/lawyer model is a successful way to intervene with victims of elder mistreatment. A conceptually-based, 


\section{ACCEPTED MANUSCRIPT}

systematic evaluation process based on advanced statistical strategies was introduced for use in future elder mistreatment program evaluation studies.

\section{Reference List}

Acierno, R., Hernandez, M.A., Amstadter, A.B., Resnick, H.S., Steve, K., Muzzy, W.,...Kilpatrick, D.G. (2010). Prevalence and correlates of emotional, physical, sexual, and financial abuse and potential neglect in the United States: The national elder mistreatment study. American Journal of Public Health, 100, 292-297. doi:10.2105/AJPH.2009.163089

Barker, N.N., \& Himchak, M.V. (2006). Environmental issues affecting elder abuse victims in their reception of community based services. Journal of Gerontological Social Work, 48, 233255. doi:10.1300/J083v48n01_16

Burnes, D., \& Lachs, M.S. (2012). Operationalization and prediction of elder mistreatment victim program outcomes: A systematic review and conceptual framework. Manuscript resubmitted for publication with revisions to the Gerontologist

Brownell, P., \& Wolden, A. (2002). Elder abuse intervention strategies: Social service or criminal justice? Journal of Gerontological Social Work, 40, 83-100. doi:10.1300/J083v40n01_06

Centers for Disease Control and Prevention (CDCP). (2007). The state of aging and health in America. Retrieved from http://apps.nccd.cdc.gov/SAHA/Default/Default.aspx

Cripps, D. (2001). Rights focused advocacy and elder abuse. Australasian Journal on Ageing, 20, 17-22. doi:10.1111/j.1741-6612.2001.tb00344.x

\section{ACCEPTED MANUSCRIPT}




\section{ACCEPTED MANUSCRIPT}

Connolly, M.T. (2008). Elder self-neglect and the justice system: An essay from an interdisciplinary perspective. Journal of the American Geriatrics Society, 56, S244-S252. doi:10.1111/j.1532-5415.2008.01976.x

Dong, X., Simon, M., \& Evans, D. (2012). Elder self-neglect and hospitalization: Findings from the Chicago health and aging project. Journal of the American Geriatrics Society, 60, 202-209. doi:10.1111/j.1532-5415.2011.03821.x

Dong, X., Simon, M., Mendes de Leon, C., Fulmer, T., Beck, T., Hebert, L.,...Evans, D. (2009). Elder self-neglect and abuse and mortality risk in a community-dwelling population. JAMA, 302, 517-26. doi:10.1001/jama.2009.1109

Ernst, J.S., \& Smith, C.A. (2012). Assessment in adult protective services: Do multidisciplinary teams make a difference? Journal of Gerontological Social Work, 55, 21-38. doi:10.1080/01634372.2011.626842

Fisher, B.S., \& Regan, S.L. (2006). The extent and frequency of abuse in the lives of older women and their relationship with health outcomes. Gerontologist, 46, 200-209. doi:10.1093/geront/46.2.200

Imbody, B., \& Vandsburger, E. (2011). Elder abuse and neglect: Assessment tools, interventions, and recommendations for effective service provision. Educational Gerontology, 37, 634-650. doi:10.1080/15363759.2011.577721

Kurrle, S.E., Sadler, P.M., Lockwood, K., \& Cameron, I.D. (1997). Elder abuse: Prevalence, intervention and outcomes in patients referred to four aged care assessment teams. Medical Journal of Australia, 166(3), 119-122. 


\section{ACCEPTED MANUSCRIPT}

Lachs, M.S., \& Berman, J. (2011). Under the radar: New York State elder abuse prevalence study. Retrieved October 15, 2011, from http://www.lifespan-

roch.org/documents/UndertheRadar051211

Lachs, M.S., Williams, C.S., O’Brien, S., \& Pillemer, K.A. (2002). Adult protective service use and nursing home placement. Gerontologist, 42, 734-739. doi:10.1093/geront/42.6.734

Lachs, M.S., Williams, C.S., O'Brien, S., Pillemer, K.A., \& Charlson, M.E. (1998). The mortality of elder mistreatment. JAMA, 280, 428-432. doi:10.1001/jama.280.5.428

Lithwick, M., Beaulieu, M., Gravel, S., \& Straka, S.M. (2000). The mistreatment of older adults: Perpetrator-victim relationships and interventions. Journal of Elder Abuse \& Neglect, 11, 95112. doi:10.1300/J084v11n04_07

Mosqueda, L., \& Dong, X. (2011). Elder abuse and self-neglect: "I don’t care anything about going to the doctor, to be honest...". JAMA, 306, 532-540. doi:10.1001/jama.2011.1085

National Research Council. (2003). Elder mistreatment: Abuse, neglect, and exploitation in an aging America. Washington, DC: The National Academy Press.

Navarro, A.E., Wilber, K.H., Yonashiro, J., \& Homeier, D.C. (2010). Do we really need another meeting? Lessons from the Los Angeles County Elder Abuse Forensic Center. Gerontologist, 50, 702-711. doi:10.1093/geront/gnq018

Neale, A.V., Hwalek, M.A., Goodrich, C.S., \& Quinn, K.M. (1996). The Illinois elder abuse system: Program description and administrative findings. Gerontologist, 36, 502-511. doi:10.1093/geront/36.4.502

\section{ACCEPTED MANUSCRIPT}




\section{ACCEPTED MANUSCRIPT}

Pillemer, K.A., Breckman, R., Sweeney, C.D., Brownell, P., Fulmer, T., Berman, J.,..Lachs, M.S. (2011). Practitioners' views on elder mistreatment research priorities: Recommendations from a research-to-practice consensus conference. Journal of Elder Abuse \& Neglect, 23, 115126. doi:10.1080/08946566.2011.558777

Ploeg, J., Fear, J., Hutchison, B., MacMillan, H., \& Bolan, G. (2009). A systematic review of interventions for elder abuse. Journal of Elder Abuse \& Neglect, 21, 187-210. doi:10.1080/08946560902997181

Roberto, K.A., Teaster, P.B., \& Duke, J.O. (2004). Older women who experience mistreatment: Circumstances and outcomes. Journal of Women \& Aging, 16, 3-16. doi:10.1300/J074v16n01_02

Schecter, M., \& Dougherty, D. (2009). Combating elder abuse through a lawyer/social worker collaborative team approach: JASA Legal/Social work elder abuse prevention program (LEAP). Care Management Journals, 10, 71-76.

Shiferaw, B., Mittelmark, M.B., Wofford, J.L., Anderson, R.T., Walls, P., \& Rohrer, B. (1994). The investigation and outcome of reported cases of elder abuse: The Forsyth county aging study. Gerontologist, 34, 123-125. doi:10.1093/geront/34.1.123

Stolee, P., Hiller, L.M., Etkin, M., \& McLeod, J. (2012). Flying by the seat of our pants: Current processes to share best practices to deal with elder abuse. Journal of Elder Abuse \& Neglect, 24, 179-194. doi:10.1080/08946566.2011.646528 


\section{ACCEPTED MANUSCRIPT}

Teaster, P.B., Nerenberg, L., \& Stansbury, K.L. (2003). A national look at elder abuse multidisciplinary teams. Journal of Elder Abuse \& Neglect, 15(3-4), 91-107. doi:10.1300/J084v15n03_06

Vladescu, D., Eveleigh, K., Ploeg, J., \& Patterson, C. (2000). An evaluation of a client-centered case management program for elder abuse. Journal of Elder Abuse \& Neglect, 11, 5-22. doi:10.1300/J084v11n04_02

Wolf, R.S., \& Pillemer, K. (1989). Helping elderly victims: The reality of elder abuse. New York: Columbia University Press

Wolf, R.S., \& Pillemer, K. (2000). Elder abuse and case outcome. Journal of Applied Gerontology, 19(2), 203-220. doi:10.1177/073346480001900206 


\section{ACCEPTED MANUSCRIPT}

Table 1

Descriptive Characteristics of Sample and Bivariate Associations with MSCC Outcome ( $\mathrm{n}=$ 233)

MSCC (level future risk)

Characteristic

$\mathrm{n}(\%)$

Reduced High/Unchanged $\chi^{2} /$ t-score

Client

Site

0.72

Manhattan

$34(14.6) \quad 22(9.4)$

$12(5.2)$

Queens

$105(45.1) \quad 70(30.0)$

$35(15.0)$

Brooklyn

$94(40.3) \quad 67(28.8)$

27 (11.6)

Referral source

$7.84 *$

Self

$47(20.3)$

$37(15.9)$

$10(4.3)$

Family

$44(19.0) \quad 23(9.9)$

$21(9.1)$

Community

$141(60.8) \quad 99(42.7) \quad 42(18.1)$ 


\section{ACCEPTED MANUSCRIPT}

Gender

2.18

Male

$48(20.6) \quad 37(15.9) \quad 11(4.7)$

Female

$185(79.4) \quad 122(52.4) \quad 63(27)$

Racial group

0.78

Caucasian

$59(29.8) \quad 41(20.7) \quad 18(9.1)$

African American

$83(41.0) \quad 61(30.8) \quad 22(11.1)$

Hispanic

$35(17.7) \quad 23(11.6)$

$12(6.1)$

Other

$21(10.6) \quad 15(7.6)$

$6(3.0)$

Age mean (SD)

$73.67(9.2)$

$-1.18$

English proficient

1.18

No

$43(19.5) \quad 123(55.7) \quad 55(24.9)$

Yes

$178(80.5) \quad 26(11.8)$

$17(7.7)$

Marital status

6.57 


\section{ACCEPTED MANUSCRIPT}

Married

Partner

Divorced

Widow

Single

Mistreatment Type

Financial

Emotional

Physical

Sexual

Neglect

Multiple

Physical health issue

No
$60(28.4) \quad 41(19.4) \quad 23(10.9)$

$4(1.9) \quad 2(0.9) \quad 2(0.9)$

$48(22.7) \quad 36(17.1) \quad 12(5.7)$

$89(42.2) \quad 65(30.8) \quad 24(11.4)$

$10(4.7) \quad 10(4.7) \quad 0(0)$

$11.28 *$

$66(28.6) \quad 43(18.6) \quad 23(10.0)$

$56(24.2) \quad 31(13.4) \quad 25(10.8)$

$66(28.6) \quad 54(23.4) \quad 12(5.2)$

$1(0.4) \quad 1(0.4) \quad 0(0.0)$

$5(2.2) \quad 3(1.3) \quad 2(0.9)$

$37(16.0) \quad 27(11.7) \quad 10(4.3)$

0.05

$16(8.9) \quad 12(6.7) \quad 4(2.2)$ 


\section{ACCEPTED MANUSCRIPT}

Yes

Dementia

No

Yes

Table 1 Continued
$163(91.1) \quad 118(65.9) \quad 45(25.1)$

$165(92.2) \quad 123(68.7) \quad 42(23.5)$

$14(7.8) \quad 7(3.9)$

$7(3.9)$

\section{MSCC (level future risk)}

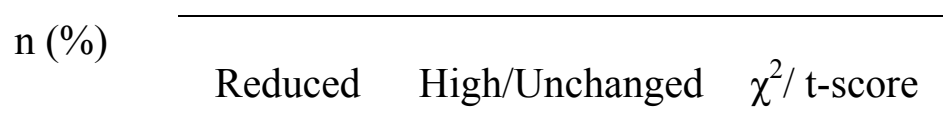

Social support

1.73

Low

$15(11.8) \quad 10(7.9) \quad 5(3.9)$

Moderate

$49(38.6) \quad 32(25.2)$

$17(13.4)$

High

$63(49.6) \quad 48(37.8)$

$15(11.8)$ 


\section{ACCEPTED MANUSCRIPT}

Living arrangement

Lives with abuser

Lives without abuser

\section{Perpetrator}

Gender

Male

Female

Relation to victim

Spouse/Partner

Child

Grandchild

Other

Substance abuse
$143(63.6) \quad 91(40.4)$

$52(23.1)$

$82(36.4) \quad 65(28.9)$

$17(7.6)$ 


\section{ACCEPTED MANUSCRIPT}

No

Yes

Retention

No

Yes

Program fidelity ratio mean (SD) $\quad 0.50(0.36)$
$72(44.7)$

$89(55.3)$
$56(34.8)$

$58(36)$
$16(9.9)$

$31(19.3)$
$167(71.7) \quad 147(63.1) \quad 20(8.6)$

$66(28.3) \quad 12(5.2) \quad 54(23.2)$

$167(71.7) \quad 147(63.1) \quad 20(8.6)$

${ }^{*} \mathrm{p}<0.05 .{ }^{* *} \mathrm{p}<0.01 .{ }^{* * *} \mathrm{p}<0.001$ 


\section{ACCEPTED MANUSCRIPT}

Table 2

Multivariate Logistic Regression for Retention, Program Fidelity, and Intervention Type as Predictors of MSCC Controlling for Key Covariates

\begin{tabular}{|c|c|c|c|c|c|c|}
\hline \multirow[b]{2}{*}{ Variable } & \multicolumn{2}{|c|}{ Model $1(n=233)$} & \multicolumn{2}{|c|}{ Model $2(n=233)$} & \multicolumn{2}{|c|}{ Model $3(n=167)$} \\
\hline & OR & $95 \% \mathrm{CI}$ & OR & $95 \% \mathrm{CI}$ & OR & $95 \% \mathrm{CI}$ \\
\hline
\end{tabular}

Predictors

Retention $\left(\mathrm{Yes}^{1}\right) \quad 0.02 * * \quad 0.01-0.05$

Program Fidelity

$0.002 * 0-0.01$

**

Multidisciplinary

$0.21 * \quad 0.06-0.75$

Type $^{2}$

Covariates

Site ID

Queens $^{3}$

$2.52 \quad 0.56$

$-\quad 2.78 \quad 0.54$

$-$

$1.83 \quad 0.22$ 


\section{ACCEPTED MANUSCRIPT}

Brooklyn

$2.59 \quad 11.38$

2.74

14.26

2.27

15.19

0.57

0.56

0.28

11.82

13.26

18.41

Referral Source
Family $^{4}$
$1.91 \quad 0.50-7.29$
1.43
$0.38-5.42$
Self
1.04
$0.32-3.39$
1.09
$0.32-3.70$
Client Female 5
$6.37 * * \quad 1.62$
$5.85^{* *}$
1.58
2.07
0.42
25.06
21.63
10.32
Racial Minority ${ }^{6}$
0.65
$0.19-2.21$
1.07
$0.33-3.50$
1.02
$0.28-3.63$
Age
0.99
$0.03-1.06$
0.97
$0.91-1.04$
0.99
$0.92-1.06$

English Proficient ${ }^{7}$

$1.83 \quad 0.56-5.98$

1.18

$0.34-4.08$

Not Married ${ }^{8}$

$0.21 * \quad 0.06-0.73$

$0.25 *$

$0.07-0.90$

0.46

$0.11-1.95$

Abuse Type 


\section{ACCEPTED MANUSCRIPT}

Emotional $^{9}$

Physical

Neglect

Multiple

Physical Health Issue ${ }^{10}$

0.92

1.44

0.06

33.53

0.72

$0.18-2.82$

$1.00-8.60$

1.89

0.31

$-$

0.54

$0.08-3.92$

11.36

Dementia $^{11}$

1.38

0.16

$-\quad 1.02$
42.29

$0.25-4.12$
11.66
Moderate $^{12}$
2.08
0.25
$-\quad 1.58$
0.20
$-$
0.74
$0.06-9.03$
High
17.32
0.54
12.48
0.65

$$
0.06-6.58
$$$$
0.06-4.97
$$

Table 2 Continued 


\section{ACCEPTED MANUSCRIPT}

\begin{tabular}{|c|c|c|c|c|c|c|}
\hline & & & & & & \\
\hline & OR & $95 \% \mathrm{CI}$ & OR & $95 \% \mathrm{CI}$ & OR & $95 \%$ CI \\
\hline Lives Without abuser ${ }^{13}$ & $0.34+$ & $0.12-1.02$ & $0.27 *$ & $0.09-0.79$ & 0.45 & $0.11-1.86$ \\
\hline Abuser Female ${ }^{14}$ & 1.20 & $0.44-3.28$ & 1.15 & $0.42-3.12$ & 0.79 & $0.22-2.79$ \\
\hline Substance & 1.40 & $0.43-4.56$ & 1.27 & $0.41-3.92$ & 2.86 & 0.65 \\
\hline Abuse $^{15}$ & & & & & & 12.62 \\
\hline Constant & 5.30 & 0.01 & 8.84 & 0.02 & 0.50 & 0.001 \\
\hline & & 3080.74 & & 4500.30 & & 252.34 \\
\hline
\end{tabular}

Note. OR $=$ Odds Ratio. $\mathrm{CI}=$ Confidence Interval. Referent groups for categorical variables:

${ }^{1}$ Not retained, ${ }^{2}$ Social work only intervention, ${ }^{3}$ Manhattan site, ${ }^{4}$ Community referral, ${ }^{5}$ Male, ${ }^{6}$ White, ${ }^{7}$ Not English proficient, ${ }^{8}$ Married/Partner, ${ }^{9}$ Financial abuse, ${ }^{10}$ No physical health issue, ${ }^{11}$ No dementia, ${ }^{12}$ Low social support, ${ }^{13}$ Lives with perpetrator, ${ }^{14}$ Male perpetrator, ${ }^{15}$ No perpetrator substance abuse. All models satisfy Hosmer-Lemeshow Goodness of Fit Test $(\mathrm{p}>0.05): \chi^{2}$ Model 1 $(8,233)=10.33$, Pseudo $\mathrm{R}_{\text {Model } 1}^{2}=0.64 ; \chi^{2}$ Model $2(8,233)=6.10$, Pseudo $\mathrm{R}_{\text {Model }}^{2}$ ${ }_{2}=0.65 ; \chi_{\text {Model } 3}^{2}(8,167)=7.66$, Pseudo $\mathrm{R}_{\text {Model } 3}^{2}=0.21$

${ }^{*} \mathrm{p}<0.05 .{ }^{* *} \mathrm{p}<0.01 .{ }^{* * *} \mathrm{p}<0.001 .+\mathrm{p}<0.06$ (borderline) 